Research Article

\title{
Tunnel Collapse Mechanism and Its Control Strategy in Fault Fracture Zone
}

\author{
Jin Zhang $\mathbb{D}$, Mengxue Wang, and Chuanhao Xi \\ College of Civil Engineering, Qingdao University of Technology, Qingdao 26033, China \\ Correspondence should be addressed to Jin Zhang; zhangin@qut.edu.cn
}

Received 6 March 2021; Revised 17 March 2021; Accepted 19 March 2021; Published 31 March 2021

Academic Editor: Haiyan Wang

Copyright (c) 2021 Jin Zhang et al. This is an open access article distributed under the Creative Commons Attribution License, which permits unrestricted use, distribution, and reproduction in any medium, provided the original work is properly cited.

Complex geological conditions such as fault fracture zone will have a significant adverse impact on tunnel engineering, and collapse, large deformation, and other problems are prominent. The research on the large deformation mechanism and control of tunnel crossing fault fracture zone can provide guidance for tunnel safety construction. Based on the Jingzhai tunnel, combined with geological analysis, theoretical research, numerical simulation, and other means, this paper studies and analyzes the large deformation mechanism of the tunnel. The control effect of different advanced reinforcement measures is studied.

\section{Introduction}

Fault is the most common adverse geological phenomenon in tunnel construction. The distribution section of fault fracture zone is the most unstable section of tunnel surrounding rock. Fault and fracture zone are the main storage place of silt zone. Silt zone is the main source of water and mud inrush in tunnel. When the geological conditions are complex, weak surrounding rock, fault fracture zone, and other unfavorable geological distribution, the tunnel is prone to geological disasters. The rock mass in fault fracture zone is characterized by low strength, weak disintegration when meeting water, wide distribution of fractures, and irregular groundwater movement. When the tunnel passes through unfavorable geology, under the combined action of geostress, water pressure, and excavation disturbance, the tunnel is prone to collapse, water inrush, mud inrush, and other disasters. Many scholars have done a lot of research on the stability of tunnel in fault fracture zone from collapse cases, internal deformation mechanism of surrounding rock, support structure, and other aspects.

Li et al. [1] studied that Epi-Fracture-Karst-Zone induced heavy mud in Lingjiao tunnel and mechanism of mud inrush induced by EFKZ has been identified. Wang et al. [2] proposed a new model for predicting water inrush in karst tunnel. The ideal point method and analytic hierarchy process (AHP) are combined to evaluate the risk of water inrush. Firstly, the ideal point method is introduced as a new water inrush risk prediction method. Secondly, the water inrush risk of karst tunnel is discussed from the perspective of influencing factors. Kun Onargan [3] investigated the dangerous area around the shallow subway tunnel in weak fault rock and determined the influence of tunnel behavior on the surface structure. Therefore, through field observation, laboratory work, and computer simulation, we try to determine the dangerous area along the tunnel. Then, the data obtained from the computer model is compared with the data obtained from the field measurement. Through a series of experiments based on finite element method, Zhang et al. [4] studied the displacement, stress, and plastic zone of surrounding rock and the stress of shotcrete lining under different conditions. At the same time, in the research methods of tunnel and other geotechnical engineering problems, the current mainstream research methods mainly include laboratory test, numerical simulation, and field monitoring [5-9].

$\mathrm{Wu}$ et al. [10, 11] summarized and analyzed the mechanism of large deformation of soft rock tunnel and introduced different support methods and their adaptive conditions. Sun et al. [12] analyzed the acoustic emission 
characteristics of rock mass failure. Wang et al. [13] proposed the risk assessment method of karst tunnel water inrush interval. On this basis, the concept and calculation form of risk assessment model are introduced, and the risk environment, construction factors, and feedback information are analyzed. Li et al. [14] analyzed the mechanism of water inrush seepage transformation caused by excavation disturbance. The potential water bearing area of the tunnel is analyzed by using electromagnetic geophysical method. The constitutive model of rock mass and grouting parameters are considered in the numerical simulation. The law of crack initiation and propagation under different curtain grouting parameters is proposed. Dai et al. [15] proposed an objective function optimization method based on firefly optimization algorithm. Using random medium theory (SMT), the HPJG effect of single pile is simulated as the superposition effect of foam slurry at the same distance. A random medium prediction model for uplift effect of HPJG piles is established. Wang et al. $[16,17]$ expounded the collapse process of tunnel affected by fault fracture zone and introduced the treatment method of collapse. Some experts [18-25] studied the deformation characteristics of the broken area of the tunnel by means of indoor similar test, numerical test, and field test.

Based on the practical engineering problems, this paper discusses the danger of tunnel crossing fault from the aspects of theoretical analysis, numerical calculation, and field measurement. At the same time, the paper puts forward the comparison of support methods such as advance grouting small pipe and advance bolt, which has guiding significance for engineering practice.

\section{Engineering Geological Conditions and Original Design Scheme}

2.1. Engineering Geology. Jingzhai tunnel is located on the middle line of Pan Asian Railway from Kunming to Bangkok, which is the administrative region of Jinghong City, Yunnan Province. This project is a single-track railway tunnel with cross-section width and height of 10.05 and $8.16 \mathrm{~m}$, respectively. The entrance mileage of the tunnel is DK $405+615$, the exit mileage is DK $415+124$, the total length is $9509 \mathrm{~m}$, and the maximum buried depth of the construction tunnel is $711 \mathrm{~m}$. The surface water and groundwater of the tunnel are relatively developed, and the groundwater is mainly bedrock fissure water and karst water. The normal water inflow of the tunnel is $44100 \mathrm{~m}^{3} / \mathrm{d}$, and the maximum water inflow in rainy season is $66150 \mathrm{~m}^{3} / \mathrm{d}$. In the original construction scheme, NATM was used for tunnel excavation, with three steps. In the process of tunnel construction, several fault fracture zones were encountered, and 12 outburst events occurred. The average deformation in the fault fracture zone was $1 \mathrm{~m}$.

From the perspective of plate tectonics, the survey area is located in the Indosinian subplate. The Sichuan-Yunnan rhombic fault block to the west of Xiaojiang Fault is sliding to the southeast, and the fault block to the east is pushing and warping to the north. It belongs to Lanping-Simao depression, which is sandwiched by Honghe fault and Lancangjiang fault and is a long strip block. Caledonian movement caused basement fold uplift and separated from Yangtze subplate. As far as the structural system is concerned, to the south is the middle part of the East Branch of the Qinghai Tibet Yunnan Myanmar Indonesia type structural system. Located in the middle part of the East Branch of the "evil shaped structure" system in Qinghai, Tibet, Yunnan, Myanmar, and Indonesia, it is composed of a series of NW-NNW trending folds and faults, mainly Ailaoshan structural belt, Mojiang structural belt, and Pu'er (Simao) structural belt. Folds and faults are parallel to each other, and they are compression and torsion structures. They are characterized by large scale, far extension, and wide distribution and tend to spread from northwest to Southeast. The corresponding NE trending tension and tension torsion faults are developed vertically and the scale is small, but the NW-NNW trending faults have been damaged to varying degrees. The whole tunnel area is located in the southeast wing of Nanguang compound anticline. Guanhan syncline and Mamaoxiaozhai gabuto fault are developed in the survey area, as shown in Figure 1.

2.1.1. Guanhan Syncline. The axis is about $\mathrm{N} 22^{\circ} \mathrm{W}$, intersecting with the line about $61^{\circ}$, and the core and wing strata are shale with mudstone and sandstone strata of Middle Jurassic Hepingxiang formation. The dip angle of the west wing is about $15^{\circ}$ to $20^{\circ}$ and the dip angle of the east wing is about $30^{\circ}$ to $40^{\circ}$ and the core of the syncline intersects with the tunnel body and DK $414+440 \sim+490$ section.

2.1.2. Mamoxiaozhai Gabuto Fault. Strike is about $\mathrm{N} 10^{\circ}$ to $30^{\circ} \mathrm{W}$, extending in wavy bending. The line intersects with the fault surface and DK $408+940$, with an angle of about $58^{\circ}$ and intersects with the tunnel body in DK $409+180+200$ section. The strike of the strata is parallel to the fault line. It is speculated that the cave body is a compressive reverse fault. The width of the fault fracture zone is about $20 \mathrm{~m}$, with strong cataclastic alteration, rhombic structure, wrinkling, dikes, and scratches. The main components of fault breccia are breccia, mudstone, and a small amount of mylonite. The hanging wall near the line is the Middle Triassic Bangsha formation, and the footwall is the upper Permian Longtan Formation and the lower Permian Maokou Formation. The fault is a large angle oblique line and is located near the line, which has a great impact on the tunnel.

2.2. Support Design Scheme. The clear height and width of the tunnel are $10.0 \mathrm{~m}$ and $9.3 \mathrm{~m}$, respectively. The principle of tunnel support is NATM, and the initial support includes advanced small conduit, steel mesh, steel arch frame, and 


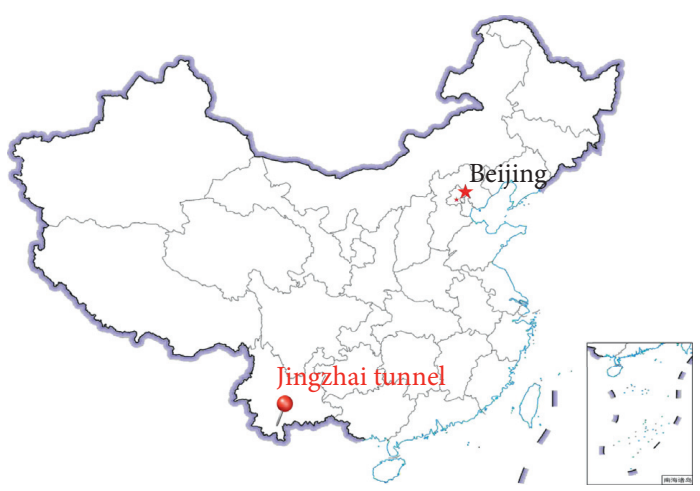

(a)

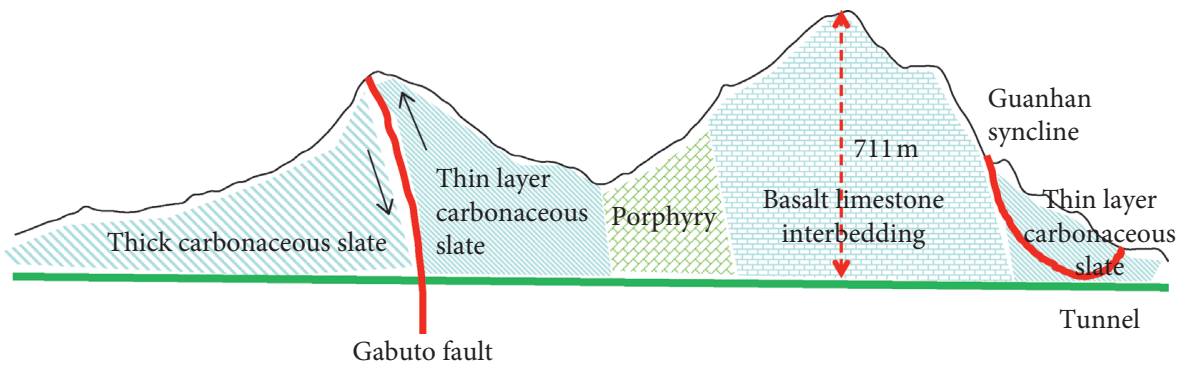

(b)

FIgURE 1: Study area and geological structure. (a) Research target location. (b) Geological structure.

early strength concrete. The specific support parameters are the following: $\Phi 42$ advance grouting small conduit $4500 \mathrm{~mm}$, spacing $400 \mathrm{~mm}$, external angle $10^{\circ}$; $\Phi 25$ self advancing hollow grouting anchor $5000 \mathrm{~mm}$, spacing $1000 * 1500 \mathrm{~mm}$; full section $\Phi 8$ steel mesh; i18 steel arch frame, spacing $500 \mathrm{~mm}$, C25 shotcrete $250 \mathrm{~mm}$; secondary lining C30 reinforced concrete $550 \mathrm{~mm}$ thick.

\section{Mechanism Analysis of Tunnel Collapse in Fault Fracture Zone}

After the tunnel is excavated, the surrounding rock around the tunnel changes from the original three-way stress state to the two-way stress state, and the geostress field is destroyed, forming a new stress distribution feature. In the process of stress redistribution, the stress distribution will generally produce three regions, and there may be a plastic zone, as shown in Figure 2.

The surrounding rock consists of three parts: low stress area (I), high stress area (II), and original stress area (III) [26]. The reason for the formation of low stress zone (I) is that the rock mass cannot bear the huge stress concentration. The high stress area (II) is the stress concentration area. Although the stress of rock mass in the area increases, it does not reach the limit of surrounding rock failure. The original stress region (III) indicates that the location is not affected by excavation disturbance. The stresses that have great influence on the failure of surrounding rock are as follows: $\sigma_{\varphi}$, tangential normal stress; $\sigma_{p}$, radial normal stress; and $\tau_{p \varphi}$, shear stress.

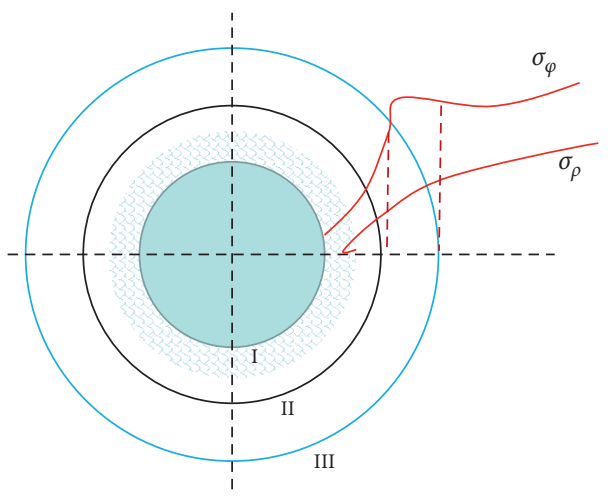

FIgURE 2: Stress state after tunnel excavation.

$$
\left\{\begin{array}{l}
\sigma_{\rho}=\frac{q(1+\lambda)}{2}\left(1-\frac{a^{2}}{\rho^{2}}\right)-\frac{q(1-\lambda)}{2}\left(1+\frac{3 a^{4}}{\rho^{4}}-\frac{4 a^{2}}{\rho^{2}}\right) \cos 2 \varphi, \\
\sigma_{\varphi}=\frac{q(1+\lambda)}{2}\left(1+\frac{a^{2}}{\rho^{2}}\right)+\frac{q(1-\lambda)}{2}\left(1+\frac{3 a^{4}}{\rho^{4}}\right) \cos 2 \varphi, \\
\tau_{\rho \varphi}=\frac{q(1-\lambda)}{2}\left(1-\frac{3 a^{4}}{\rho^{4}}+\frac{2 a^{2}}{\rho^{2}}\right) \sin 2 \varphi .
\end{array}\right.
$$

In the formula, $\sigma_{\rho}$ is radial normal stress; $\sigma_{\varphi}$ is tangential normal stress; $\tau_{\rho \varphi}$ is shear stress; $q$ is vertical uniform pressure of surrounding rock; $a$ is tunnel radius; $\lambda$ is lateral uniform pressure coefficient; and $\varphi$ is location angle around the tunnel. 
According to the above formula, the stress distribution after tunnel excavation is related to the tunnel depth, tunnel radius, and lateral pressure coefficient. Under the influence of the fault area, the horizontal pressure on the tunnel is larger, so the plastic zone and stress concentration will be more significant.

The failure conditions of rock mass discontinuities are as follows [27]:

$$
\sigma_{1}=\sigma_{3}-\frac{2\left(c+\sigma_{3} \tan \varphi\right)}{(1-\tan \varphi \cos \alpha) \sin 2 \alpha} .
$$

In the formula, $\sigma_{1}$ is maximum principal stress; $\sigma_{3}$ is minimum principal stress; and $\alpha$ is angle between structural plane and maximum principal stress plane.

It can be concluded that

$$
\left(\frac{\sigma_{3}+\sigma_{1}}{2}+\frac{\sigma_{3}-\sigma_{1}}{2} \cos 2 \alpha\right) f A<\left(\frac{\sigma_{3}-\sigma_{1}}{2} \cos 2 \alpha\right) A,
$$

where $A$ is the friction surface area of rock mass with discontinuity and $f$ is the friction coefficient.

The failure condition of structural plane is

$$
\sigma_{1}<\sigma_{3} \frac{f \cos 2 \alpha-f-\sin 2 \alpha}{f \cos 2 \alpha+f-\sin 2 \alpha} .
$$

\section{Numerical Simulation}

4.1. Model Establishment and Parameters. In this paper, three-dimensional discrete element software is used for numerical calculation. 3DEC is a calculation and analysis program based on discrete element method to describe the mechanical behavior of discrete media. The physical medium usually presents discontinuous or discrete characteristics. The discrete characteristics here can be expressed as discontinuities in the sense of material properties or meso and macro structure. The essence of discrete composition determines that the medium also presents discontinuous characteristics in the sense of mechanics, that is, the deformation discontinuity of discrete medium when it is stressed. Discrete media can be defined as the aggregate of continuous media, and continuous media interact with each other through discontinuous features. Taking rock mass as an example of general interpretation, rock blocks with different lithological properties (Continuum) and geological discontinuities (discontinuous features) constitute the most basic elements of rock mass. Under the action of external force, rock blocks can behave as continuous medium mechanical behavior, and the interaction between rock blocks is realized through discontinuities (discontinuous features). When the stress of discontinuities exceeds their bearing capacity limit, rock blocks can act as continuous medium mechanical behavior rock blocks are shear dislocation or detachment.

Due to the obvious geological characteristics of the dominant joint angle of the surrounding rock in the large deformation section of the tunnel, the deformation around the tunnel, the surrounding rock pressure, and the steel stress also reflect the obvious asymmetric distribution phenomenon. In order to truly simulate the special characteristics of the surrounding rock, the deformation characteristics of the soft rock tunnel in the high geostress fault fracture zone are obtained, and the corresponding numerical model is established. The initial stress field of rock mass in the calculation model only considers its gravity stress field. The buried depth of the model is $500 \mathrm{~m}$, and the geostress is applied on the top surface of the model to simulate the stress caused by the self-weight of the overlying strata. Elasticplastic constitutive model is used for surrounding rock and Coulomb slip constitutive model is used for joints. The width of the calculation model is $50 \mathrm{~m}$, the height of the model is $50 \mathrm{~m}$, and the longitudinal length of the tunnel is $50 \mathrm{~m}$. The tunnel model is shown in Figure 3.

It is not feasible to select the mechanical parameters of engineering rock mass directly from the experimental data, and the selection of numerical calculation parameters is one of the key problems in the study of geotechnical engineering, which plays a vital role in the calculation results. The selection of parameters not only needs to consider the rock strength and other rock-solid properties but also needs to combine the occurrence environment and structural characteristics of rock mass. At present, the rock classification standards mainly include the following: RMR (rock mass rating), RQD (rock quality design), RMI (rock mass index), and GSI. Hoek established a set of methods based on GSI geological classification index and used the following formula to transform rock strength [28], and the calculated parameters are shown in Table 1.

$$
\begin{aligned}
\frac{E_{r m}}{E_{i}} & =\left(0.02+\frac{1-(D / 2)}{1+e^{(60+15 D-G S I) / 11}}\right), \\
\sigma_{c \text { mass }} & =\sigma_{c i} \frac{\left(m_{b}+4 s-a\left(m_{b}-8 s\right)\right)}{2(1+a)(2+a)}\left(\frac{m_{b}}{4+s}\right)^{a s-1}, \\
m_{b} & =m_{i} \exp \left(\frac{\mathrm{GSI}-100}{28-14 D}\right), \\
s & =\exp \left(\frac{\mathrm{GSI}-100}{9-3 D}\right), \\
a & =\frac{1}{2}+\frac{1}{6}\left(e^{-(\mathrm{GSI} / 15)}-e^{-(20 / 3)}\right) .
\end{aligned}
$$

In the formula, $E_{r m}$ is elastic modulus of rock mass; $\sigma_{c \text { mass }}$ is uniaxial compressive strength of rock mass; GSI is geological strength index; $E_{i}$ is deformation modulus of rock; and $\sigma_{c i}$ is uniaxial compressive strength of intact rock and damage coefficient of rock mass $D=0.5$.

4.2. Calculation Results. The tunnel moves forward $10 \mathrm{~m}$ from the starting position of the fault. In this process, the left side of the tunnel first enters the fault area. The displacement of the surrounding rock on the left and right sides of the tunnel is larger than that on the right side.

The maximum displacement is $50 \mathrm{~cm}$ at the junction of the second and third steps of the left oval tunnel. The 


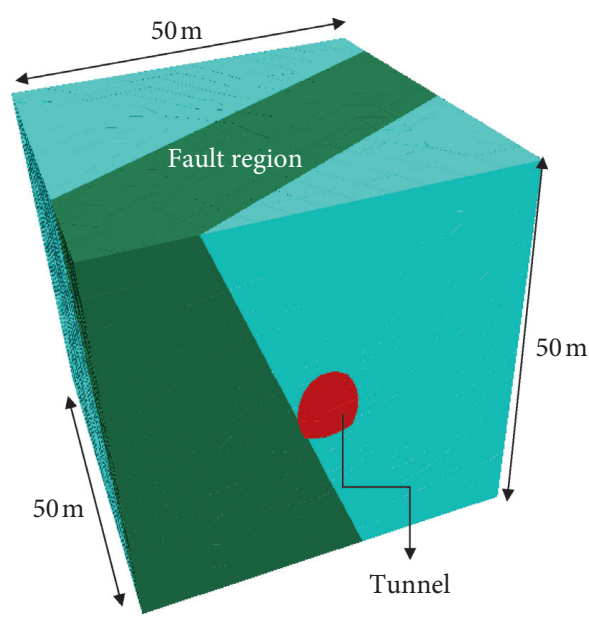

(a)

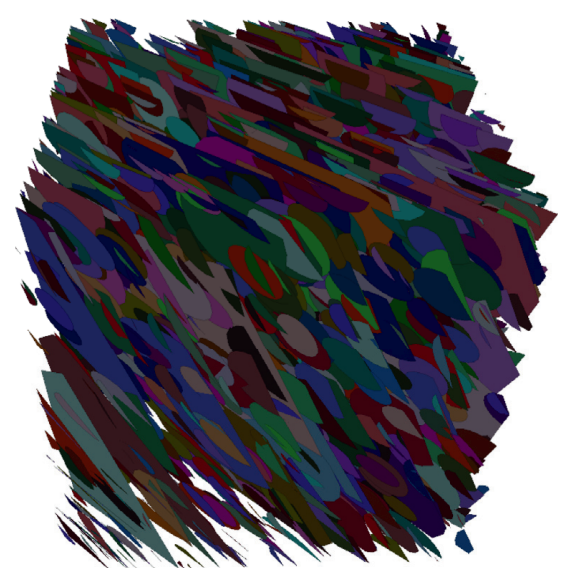

(b)

FIgURE 3: Numerical simulation model. (a) Tunnel model. (b) DFN model crack modelling.

TABLE 1: Calculation parameters.

\begin{tabular}{|c|c|c|c|c|c|c|c|c|c|c|c|}
\hline \multirow[b]{2}{*}{ Lithology } & \multicolumn{6}{|c|}{ Rock mass parameters } & \multicolumn{5}{|c|}{ Structural plane parameters } \\
\hline & $\begin{array}{l}\text { Density } \\
\left(\mathrm{kg} / \mathrm{m}^{3}\right)\end{array}$ & $K(\mathrm{GPa})$ & $G(\mathrm{GPa})$ & $C^{b}(\mathrm{MPa})$ & $\varphi^{b}$ & $\sigma_{t}^{b}(\mathrm{MPa})$ & $K^{n}(\mathrm{GPa})$ & $k^{s}(\mathrm{GPa})$ & $C^{j}(\mathrm{MPa})$ & $\varphi^{j}$ & $\sigma_{t}^{j}(\mathrm{MPa})$ \\
\hline Carbonaceous slate & 2488 & 0.47 & 0.28 & 1.8 & 22 & 0.45 & 32.12 & 12.11 & 3.69 & 29 & 3.87 \\
\hline $\begin{array}{l}\text { Rock mass parameters in } \\
\text { fault }\end{array}$ & 2467 & 0.33 & 0.11 & 1.23 & 20 & 0.31 & 12.38 & 4.33 & 2.55 & 20 & 1.26 \\
\hline
\end{tabular}

maximum displacement of the right side is $30 \mathrm{~cm}$. The surrounding rock in the fault fracture zone is relatively broken, and its mechanical properties are poor compared with those in other parts. During the excavation process, the vault settlement, arch bottom uplift, and horizontal convergence of the tunnel body in the fault fracture zone are larger than those outside the zone (Figure 4).

In this process, the right side of the tunnel gradually enters into the fault area, and finally the fault areas on the left and right sides of the tunnel are basically the same. In the fault area, the displacement of the surrounding rock on the left and right sides of the tunnel is large, and the deformation on both sides gradually changes from the large deformation on the left side to the basic symmetrical deformation. The maximum displacement occurs at the junction of two and three steps of the left elliptical tunnel (Figure 5).

The tunnel moves forward $30 \mathrm{~m}$ from the starting position of the fault. In this process, the tunnel is gradually separated from the fault area, and the left side of the tunnel is prior to the right side of the tunnel. In the fault area, the displacement of the surrounding rock on the left and right sides of the tunnel is large, and the deformation on both sides gradually changes from the large deformation on the left side to the basic symmetrical deformation. The maximum displacement occurs at the junction of two and three steps of the left elliptical tunnel (Figure 6).

The tunnel moves forward $50 \mathrm{~m}$ from the starting position of the fault, and the deformation details in the fault area are larger than those in the areas not affected by fault.
The maximum deformation is from the left side of the tunnel to the right side of the tunnel. The maximum deformation of the areas not affected by fault is about $33 \mathrm{~cm}$, and the maximum deformation of fault area is up to $60 \mathrm{~cm}$ (Figure 7).

\section{Study on Construction Scheme and Parameter Optimization of Tunnel in Fault Fracture Zone}

Through the numerical simulation analysis of tunnel geological investigation and excavation influence law, it can be known that the construction of the tunnel passing through the fault fracture zone is more dangerous. In order to ensure the construction safety in the process of tunnel excavation, this paper analyzes and studies the reinforcement effect of the advanced reinforcement scheme for the fault fracture zone tunnel, finds out the optimal advanced reinforcement scheme, and optimizes the parameters.

In this paper, advanced bolt and advanced grouting small pipe reinforcement schemes are selected. The variation law of surrounding rock in the fault fracture zone is compared and analyzed when the two schemes and the tunnel without advanced support are excavated (Figures 8-10).

The results show that the deformation curve of tunnel surrounding rock is basically the same under the working conditions of no advance support, advance anchor, and no grouting advance small conduit, which indicates that the 


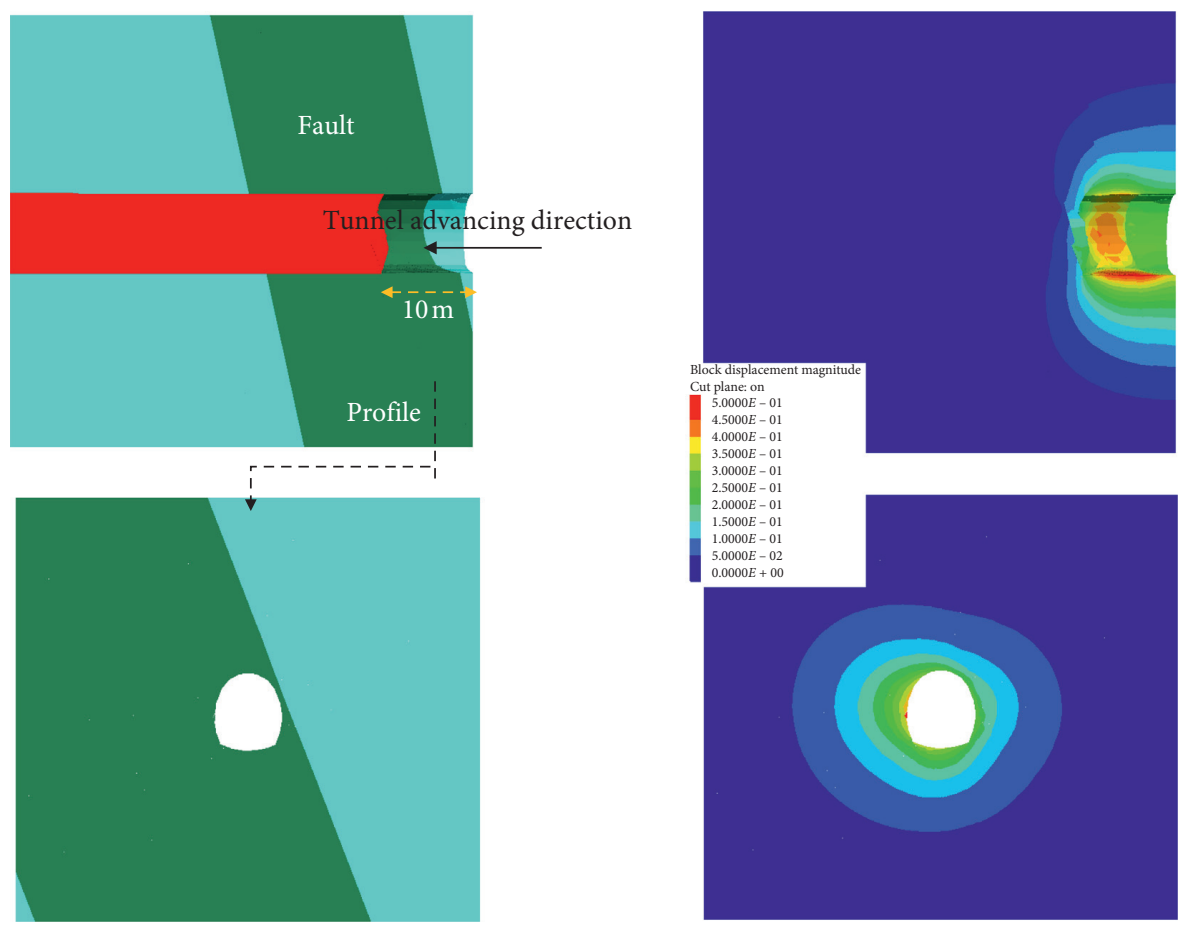

FIgURE 4: The range of tunnel entering fault is $10 \mathrm{~m}$.
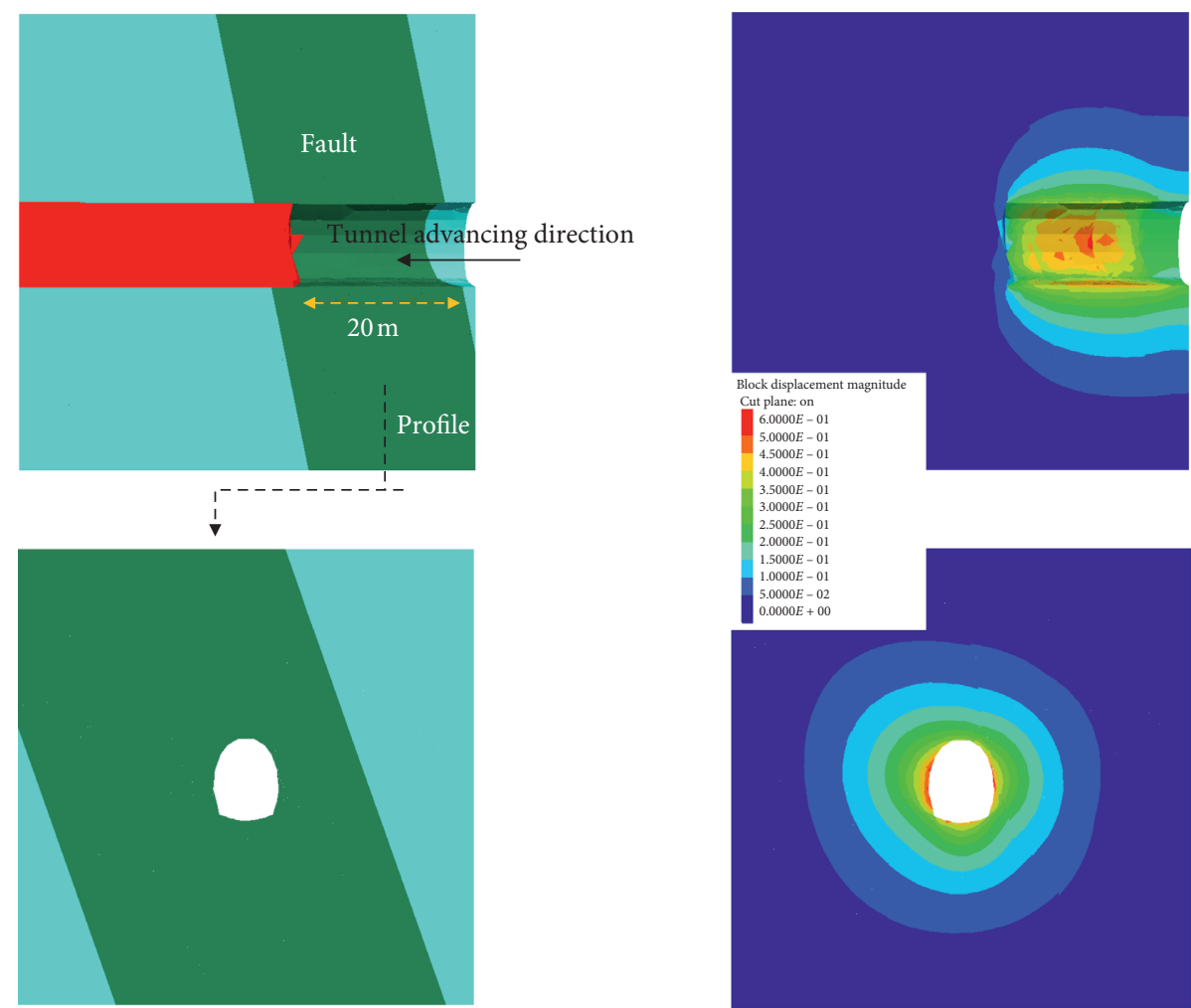

Figure 5: The tunnel enters the fault area of $20 \mathrm{~m}$.

effect of advance anchor and no grouting small conduit on the reinforcement of tunnel surrounding rock in fault fracture zone is not obvious. This is due to the low bending strength of anchor rod and small pipe itself. The effect of small advance grouting pipe on the reinforcement of tunnel surrounding rock is obvious. The larger the grouting radius is, the better the effect of surrounding rock deformation control is. 

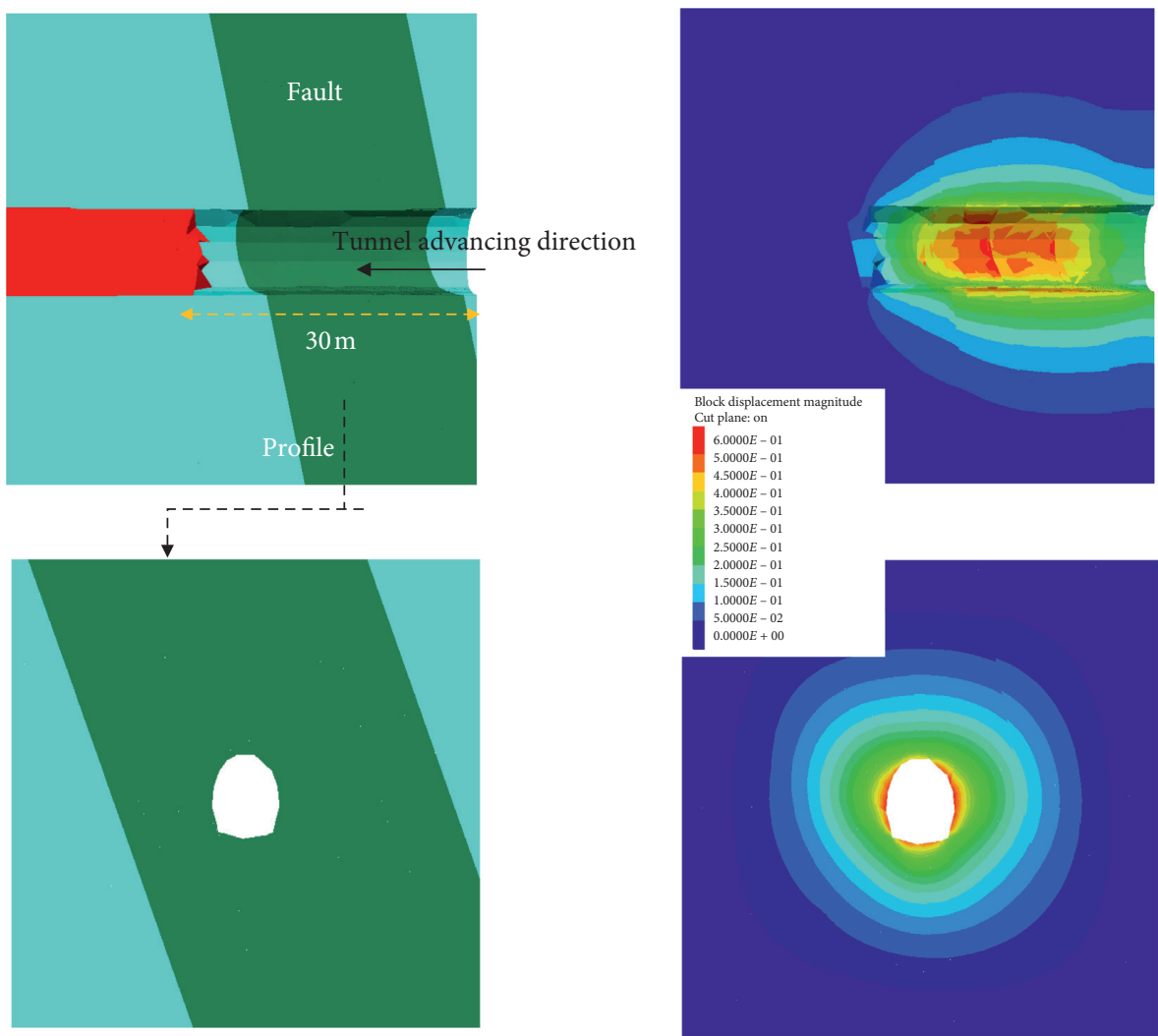

$4.5000 E-01$

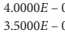

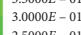

$2.5000 E-01$
$2.0000 E-01$

$2.0000 E-01$
$1.5000 E-01$
$1.000 E-0.5$

$5.0000 E-02$
$0.0000 E+00$

Figure 6: The range of the tunnel into the fault is $30 \mathrm{~m}$.

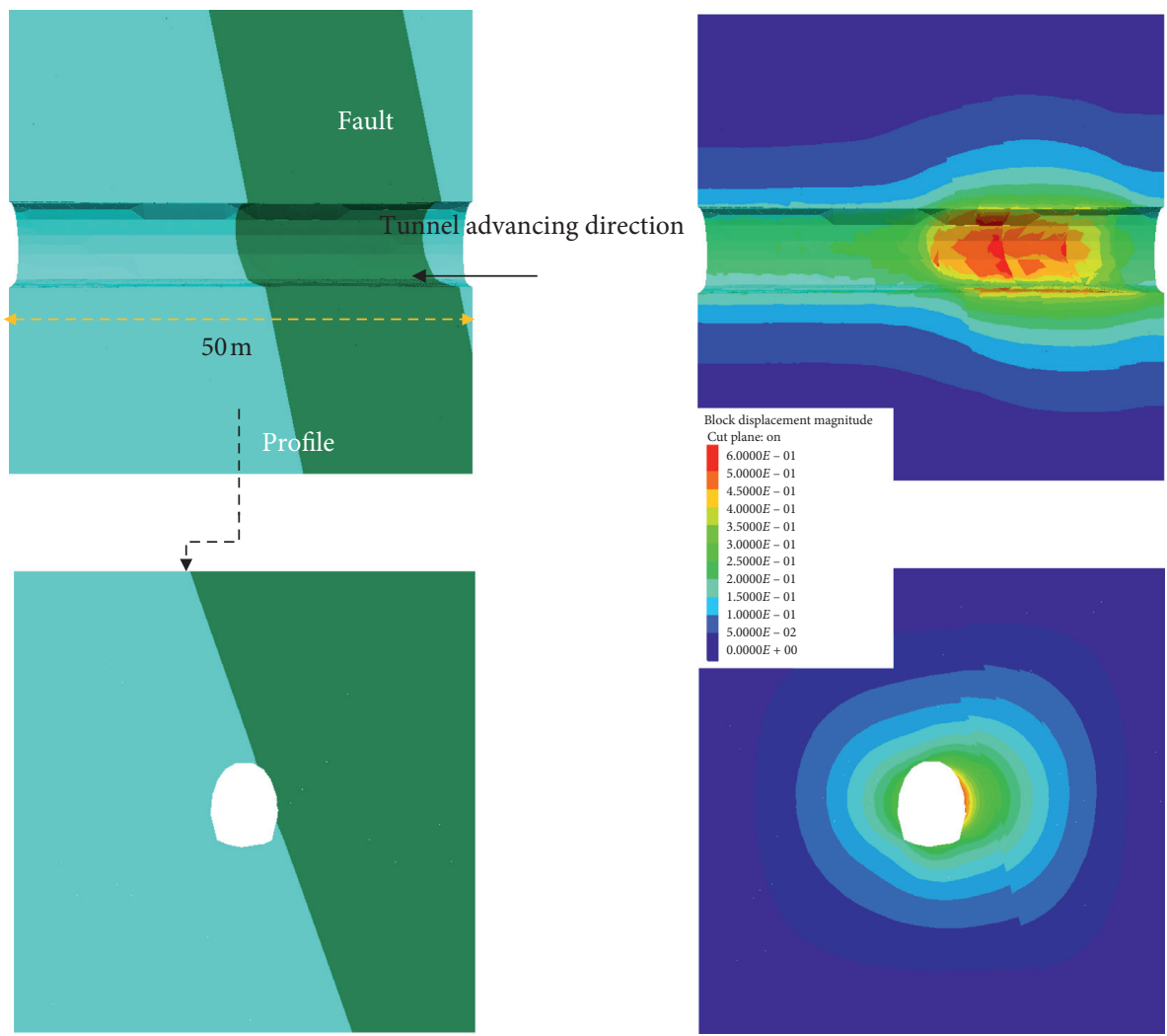

Figure 7: $50 \mathrm{~m}$ of tunnel entering fault. 

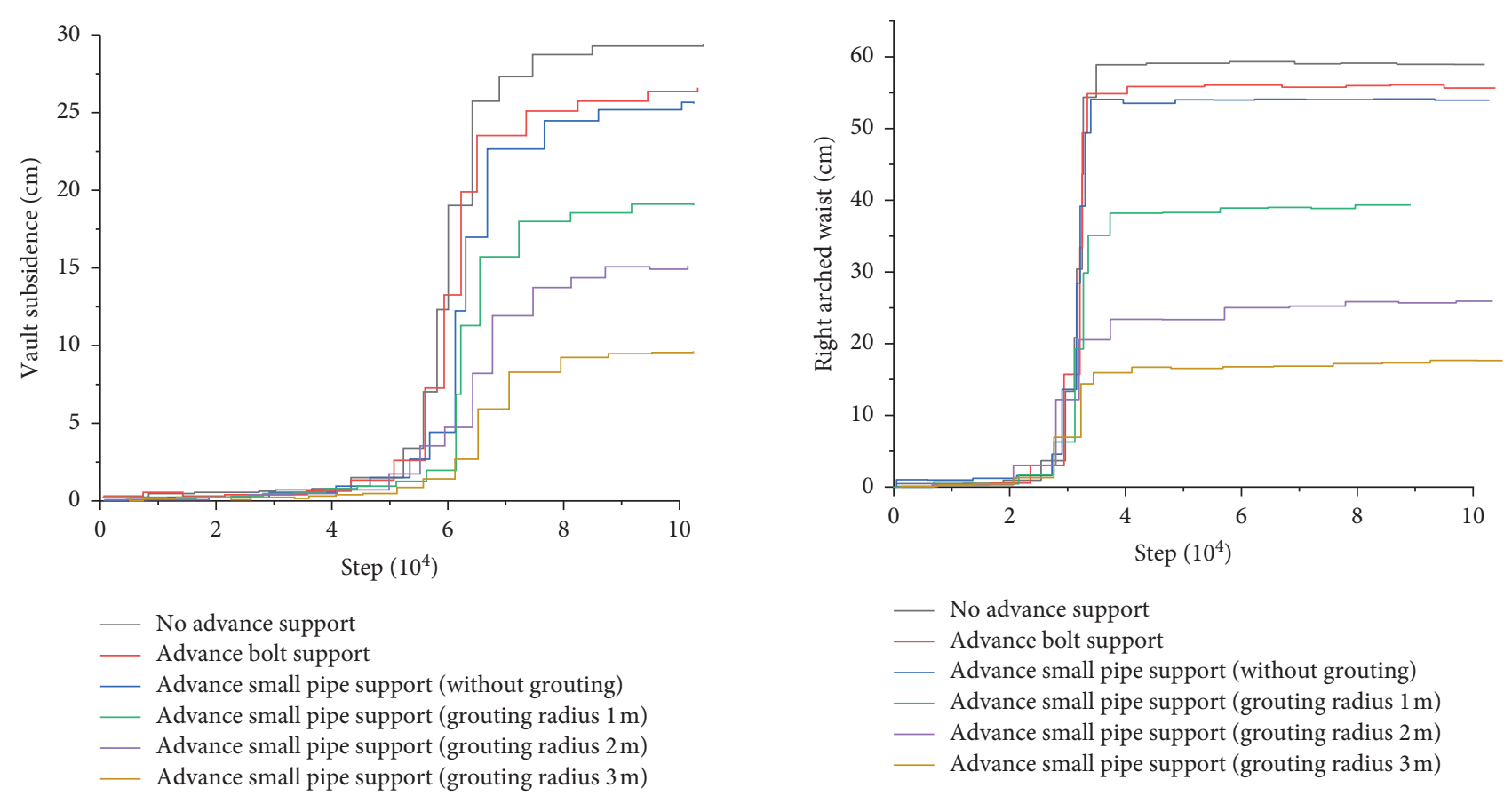

Figure 8: Vault subsidence characteristics under different advanced support schemes.

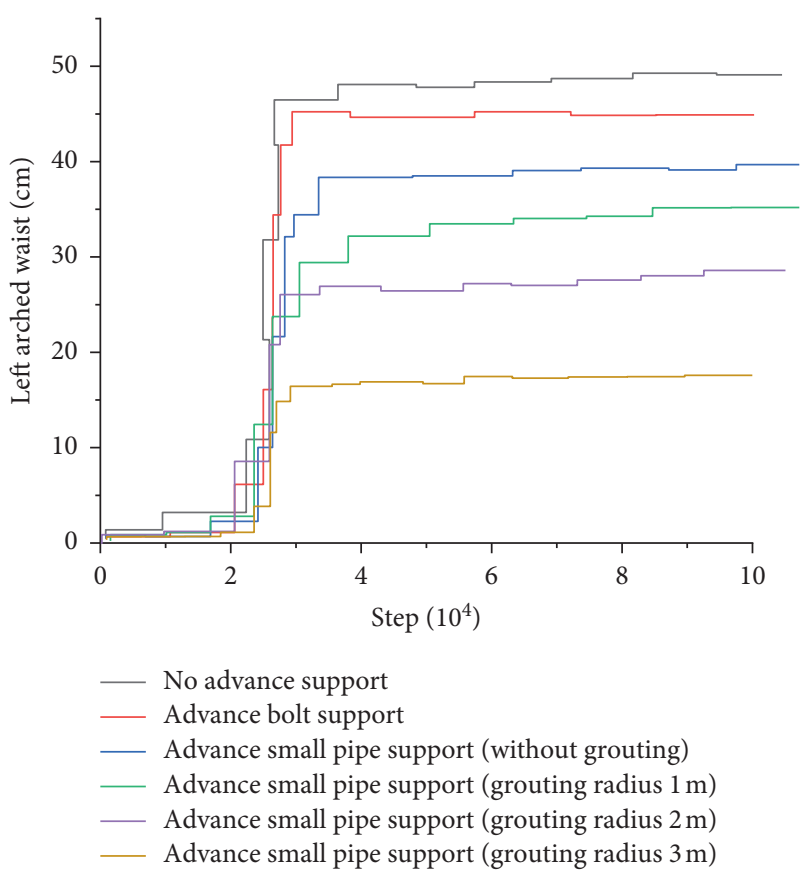

FIGURE 9: Convergence characteristics of left arch waist under different advanced support schemes.

The maximum settlement of the surrounding rock vault without grouting reinforcement is $29.88 \mathrm{~cm}$, and the maximum settlement of the vault with the thickness of $1 \mathrm{~m} \sim 3 \mathrm{~m}$ in the grouting reinforcement area is $20.11 \mathrm{~cm}$, $14.87 \mathrm{~cm}$, and $8.6 \mathrm{~cm}$, respectively, which is $32.7 \%, 50.2 \%$, and $71.2 \%$ lower than that without grouting reinforcement.

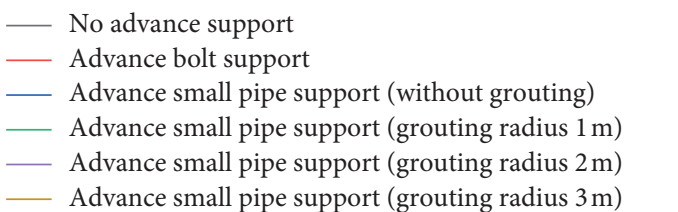

Figure 10: Convergence characteristics of right arch waist under different advanced support schemes.

It can be seen that the thicker the grouting reinforcement area is, the smaller the settlement of the surrounding rock vault is.

The maximum deformation of the left arch waist of surrounding rock without grouting reinforcement is $48.76 \mathrm{~cm}$, and that of the left arch waist with the thickness of $1 \mathrm{~m} \sim 3 \mathrm{~m}$ in grouting reinforcement area is $32.19 \mathrm{~cm}, 26.32 \mathrm{~cm}$, and $15.33 \mathrm{~cm}$, which is $34.0 \%, 46.0 \%$, and $68.5 \%$ lower than that of the arch crown without grouting reinforcement.

The maximum deformation of the right arch waist of the surrounding rock without grouting reinforcement is $58.21 \mathrm{~cm}$, and the left arch waist with the thickness of $1 \mathrm{~m} \sim 3 \mathrm{~m}$ in the grouting reinforcement area is $35.67 \mathrm{~cm}$, $24.37 \mathrm{~cm}$, and $16.31 \mathrm{~cm}$, which is $38.7 \%, 58.3 \%$, and $71.9 \%$ lower than the maximum settlement of the vault without grouting reinforcement.

\section{Conclusion}

Taking Jingzhai tunnel as the background, combined with field investigation, theoretical analysis, numerical simulation, and other means, this paper analyzes the deformation characteristics of the tunnel in the process of crossing the fault fracture zone and studies the advance reinforcement effect under six different advance support conditions.

The main conclusions are as follows:

(1) The strength of surrounding rock in tunnel fault fracture zone is low, and the tunnel excavation leads to stress concentration, which aggravates the instability and collapse of the tunnel. Due to the change of rock dip angle and the position of soft and hard rock discontinuity, the deformation is obviously asymmetric. 
(2) In advance support, advance bolt and no grouting advance small pipe cannot effectively control surrounding rock deformation, so it is necessary to select advance grouting small pipe to reinforce surrounding rock.

(3) With the increase of the thickness of grouting reinforcement zone, the deformation of surrounding rock in fault fracture zone decreases obviously. From the point of view of economy and construction, the grouting radius of $2 \mathrm{~m}$ can effectively control the deformation.

\section{Data Availability}

The data are available and are explained in this article; readers can access the data supporting the conclusions of this study.

\section{Conflicts of Interest}

The authors declare that there are no conflicts of interest.

\section{Acknowledgments}

This research was supported by the National Natural Science Foundation of China Youth Fund Project (41702320).

\section{References}

[1] X. Li, P. Zhang, Z. He, Z. Huang, M. Cheng, and L. Guo, "Identification of geological structure which induced heavy water and mud inrush in tunnel excavation: a case study on Lingjiao tunnel," Tunnelling and Underground Space Technology, vol. 69, pp. 203-208, 2017.

[2] Y. Wang, X. Yin, F. Geng, H. Jing, H. Su, and R. Liu, "Risk assessment of water inrush in karst tunnels based on the efficacy coefficient method," Polish Journal of Environmental Studies, vol. 26, no. 4, 2017.

[3] M. Kun and T. Onargan, "Influence of the fault zone in shallow tunneling: a case study of Izmir metro tunnel," Tunnelling and Underground Space Technology, vol. 33, pp. 34-45, 2013.

[4] Z. Zhang, F. Chen, N. Li, G. Swoboda, and N. Liu, "Influence of fault on the surrounding rock stability of a tunnel: location and thickness," Tunnelling and Underground Space Technology, vol. 61, pp. 1-11, 2017.

[5] Z. Tao, C. Zhu, M. He, and M. Karakus, "A physical modelingbased study on the control mechanisms of negative Poisson's ratio anchor cable on the stratified toppling deformation of antiinclined slopes," International Journal of Rock Mechanics and Mining Sciences, vol. 138, Article ID 104632, 2021.

[6] Q.-X. Meng, W.-Y. Xu, H.-L. Wang, X.-Y. Zhuang, W.-C. Xie, and T. Rabczuk, "DigiSim - an open source software package for heterogeneous material modeling based on digital image processing," Advances in Engineering Software, vol. 148, Article ID 102836, 2020.

[7] C. Zhu, M. C. He, M. Karakus, and H. Zhang, "Numerical simulations of the failure process of anaclinal slope physical model and control mechanism of negative Poissons ratio cable," Bulletin of Engineering Geology and the Environment, vol. 80, pp. 3365-3380, 2021.
[8] Y. Wang, W. K. Feng, R. L. Hu, and C. H. Li, "Fracture evolution and energy characteristics during marble failure under triaxial fatigue cyclic and confining pressure unloading (FC-CPU) conditions," Rock Mechanics and Rock Engineering, vol. 54, pp. 799-818, 2021.

[9] H. Huang, T. Babadagli, H. Li, K. Develi, and D. Zhou, "A visual experimental study on proppants transport in rough vertical fractures," International Journal of Rock Mechanics and Mining Sciences, vol. 134, Article ID 104446, 2020.

[10] K. Wu, Z. Shao, S. Qin, W. Wei, and Z. Chu, "A critical review on the performance of yielding supports in squeezing tunnels," Tunnelling and Underground Space Technology, vol. 114, no. 1 , p. 2021, 2021.

[11] K. Wu, Z. Shao, and S. Qin, "An analytical design method for ductile support structures in squeezing tunnels," Archives of Civil and Mechanical Engineering, vol. 20, no. 3, pp. 1-13, 2020.

[12] H. Sun, X. L. Liu, and J. B. Zhu, "Correlational fractal characterisation of stress and acoustic emission during coal and rock failure under multilevel dynamic loading," International Journal of Rock Mechanics and Mining Sciences, vol. 117, pp. 1-10, 2019.

[13] X. Wang, S. Li, Z. Xu, X. Li, P. Lin, and C. Lin, “An interval risk assessment method and management of water inflow and inrush in course of karst tunnel excavation," Tunnelling and Underground Space Technology, vol. 92, Article ID 103033, 2019.

[14] G. Li, W. Ma, S. Tian, Z. Hongbo, F. Huabin, and W. Zou, "Groundwater inrush control and parameters optimization of curtain grouting reinforcement for the Jingzhai tunnel," Geofluids, vol. 2021, Article ID 6634513, 10 pages, 2021.

[15] W. Dai, L. Liang, and B. Zhang, "Firefly optimization algorithm for the prediction of uplift due to high-pressure jet grouting," Advances in Civil Engineering, vol. 2020, Article ID 8833784, 12 pages, 2020.

[16] Y. Wang, H. Chang, J. Wang, X. Shi, and J. Qiu, "Countermeasures to treat collapse during the construction of road tunnel in fault zone: a case study from the Yezhuping tunnel in south Qinling, China," Environmental Earth Sciences, vol. 78 , no. 15 , pp. 1-16, 2019.

[17] L. Gan, M. Weibin, T. Siming, and Z. Wenhao, "Effects of high-pretension support system on soft rock large deformation of perpendicularly crossing tunnels," Advances in Civil Engineering, vol. 2020, Article ID 6669120, 18 pages, 2020.

[18] B. Li, R. Bao, Y. Wang, R. Liu, and C. Zhao, "Permeability evolution of two-dimensional fracture networks during shear under constant normal stiffness boundary conditions," Rock Mechanics and Rock Engineering, vol. 54, no. 1, pp. 409-428, 2021.

[19] Q. Wang, H. Gao, B. Jiang, S. Li, M. He, and Q. Qin, "In-situ test and bolt-grouting design evaluation method of underground engineering based on digital drilling," International Journal of Rock Mechanics and Mining Sciences, vol. 138, Article ID 104575, 2021.

[20] Q. Wang, Q. Qin, B. Jiang et al., "Mechanized construction of fabricated arches for large-diameter tunnels," Automation in Construction, vol. 124, Article ID 103583, 2021.

[21] A. Li, F. Dai, Y. Liu, H. Du, and R. Jiang, "Dynamic stability evaluation of underground cavern sidewalls against flexural toppling considering excavation-induced damage," Tunnelling and Underground Space Technology, vol. 112, Article ID 103903, 2021. 
[22] G. Li, Y. Hu, Q.-B. Li, T. Yin, J.-X. Miao, and M. Yao, "Inversion method of in-situ stress and rock damage characteristics in dam site using neural network and numerical simulation-a case study," IEEE Access, vol. 8, pp. 46701-46712, 2020.

[23] H. Wang, X. Fang, F. Du et al., "Three-dimensional distribution and oxidation degree analysis of coal gangue dump fire area: a case study," Science of The Total Environment, vol. 772, Article ID 145606, 2021.

[24] C. Xin, F. Du, K. Wang, C. Xu, S. Huang, and J. Shen, "Damage evolution analysis and gas-solid coupling model for coal containing gas," Geomechanics and Geophysics for GeoEnergy and Geo-Resources, vol. 7, no. 1, pp. 1-15, 2021.

[25] C. Zhu, M. He, Q. Yin, and X. Zhang, "Numerical simulation of rockfalls colliding with a gravel cushion with varying thicknesses and particle sizes," Geomechanics and Geophysics for Geo-Energy and Geo-Resources, vol. 7, no. 1, pp. 1-15, 2021.

[26] C. Tang, "Numerical simulation of progressive rock failure and associated seismicity," International Journal of Rock Mechanics and Mining Sciences, vol. 34, no. 2, pp. 249-261, 1997.

[27] J. Liu, Z. Li, and Z. Zhang, "Stability analysis of block in the surrounding rock mass of a large underground excavation," Tunnelling and Underground Space Technology, vol. 19, no. 1, pp. 35-44, 2004.

[28] M. Cai, P. K. Kaiser, H. Uno, Y. Tasaka, and M. Minami, "Estimation of rock mass deformation modulus and strength of jointed hard rock masses using the GSI system," International Journal of Rock Mechanics and Mining Sciences, vol. 41, no. 1, pp. 3-19, 2004. 